\section{Manual Clínico do Transtorno do Déficit de Atenção/Hiperatividade}

Walter Camargo Jr e Ana G Hounie. Editora Info, 2005, 1.137 pags. ISBN 8599516019

O “Manual Clínico do Transtorno do Déficit de Atenção/ Hiperatividade" (TDAH) é um lançamento oportuno, além de constituir uma agradável novidade: uma mídia eletrônica em CD-ROM - um formato de mídia que possibilitou uma interface inteligente e amigável, com ferramentas que facilitam a leitura, tornando mais fácil manipular suas mais de mil páginas do que seria no papel (para os que não abrem mão da leitura em papel, o livro permite a impressão de suas páginas para leitura). Alguns exemplos das ferramentas: basta clicar sobre o capítulo desejado, no índice, para saltar ao início dele; o acesso às tabelas, figuras e gráficos ao alcance do clique do mouse e com o imediato retorno ao trecho do livro que se estava lendo; cada referência bibliográfica pode ser visualizada simplesmente passando o ponteiro do mouse sobre sua citação; os balões de texto são também usados para a inserção de comentários complementares ao texto, tornando sua leitura mais estimulante e atrativa.

O lançamento é oportuno devido à carência de literatura sobre TDAH direcionada a psiquiatras clínicos. Dos poucos livros disponíveis em nosso país sobre o tema, a maioria se destina ao público leigo; destes, alguns muito bons, como "No Mundo da Lua", do colega Paulo Mattos, e "TDA/TDAH", do psicólogo americano Thomas Phelan; outros, infelizmente, parecem ter se rendido a algo que o mercado enxerga como mais um "modismo", possuindo um apelo nitidamente "publicitário", e mais atrapalham do que ajudam o entendimento dos pacientes que nos procuram, a ponto de ter se tornado corriqueiro receber pacientes bipolares com um exemplar desses embaixo do braço acreditando piamente ter TDAH. Mas, felizmente, há livros que vêm para acrescentar, e muito. É o caso desse Manual Clínico, cujo conteúdo vai muito além do que o modesto título sugere. É uma obra abrangente, a mais completa que temos em português, e não fica a dever para qualquer obra semelhante em outra língua. O caráter abrangente e aprofundado da obra tampouco a torna exclusiva para iniciados no tema; pelo contrário, o iniciante no estudo e/ou na clínica do TDAH se sentirá à vontade nessas páginas, pois os autores obtiveram sucesso na transmissão de um saber adquirido após anos de experiência clínica. O livro ainda pode ser utilizado como um guia de referência rápido; por exemplo, na hora em que se deseja saber como se faz a titulação da dose de um psicoestimulante, ou ainda verificar rapidamente qual, dentre as apresentações de metilfenidato disponíveis no mercado brasileiro, é a mais indicada para determinado paciente, considerando as comorbidades que apresenta, ou ainda como manejar os efeitos adversos mais freqüentes das medicações mais prescritas.

O livro inova ao reunir, entre os seus 52 autores, aqueles com expertise acadêmica em suas áreas a autores com grande experiência clínica, fornecendo em alguns capítulos o estado de arte naquele tópico e, em outros, relatos de caso narrados com fluidez que facilita a imersão na clínica do TDAH. A abordagem multidisciplinar amplia tanto a compreensão da

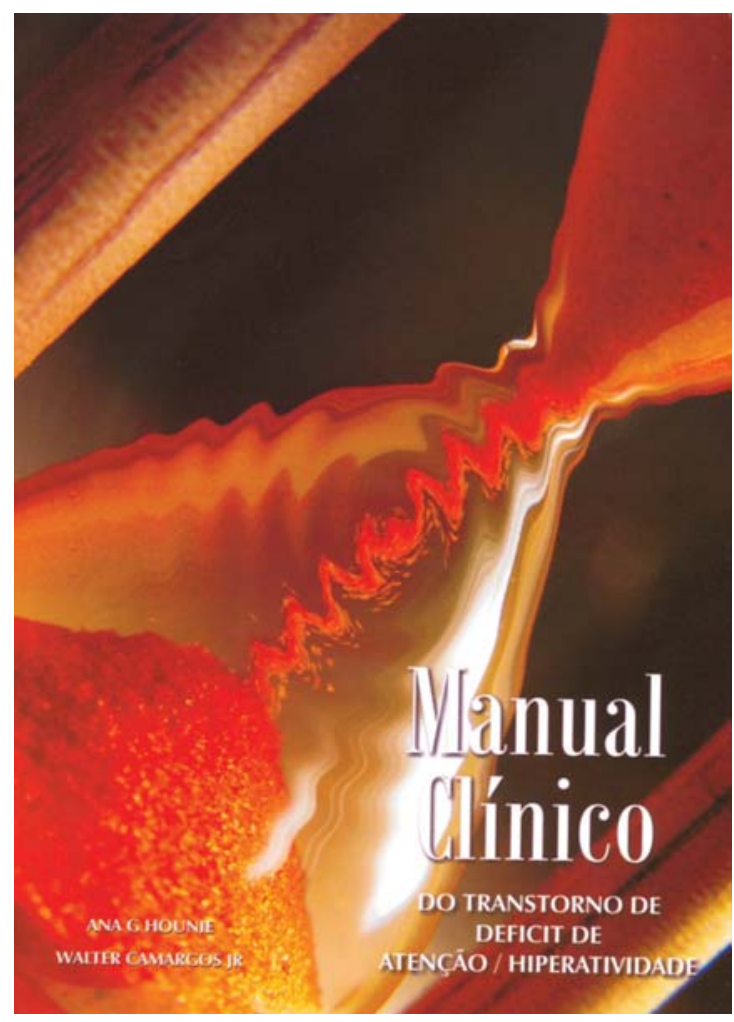

síndrome como o leque de opções terapêuticas. A obra é composta por 29 capítulos distribuídos em quatro seções: 1) Fundamentos do TDAH: Histórico e Epidemiologia, Atenção, Memória, Neuropsicologia, Neuroquímica, Lobos Frontais, Genética, Escola, e O Perfil das Famílias Brasileiras nos Grandes Centros. 2) Aspectos Clínicos: O Exame Psiquiátrico da Criança, Exame Neurológico da Criança, O Adolescente, TDAH em Adultos, e Vida Conjugal, Família e Trabalho. 3) Comorbidades e Diagnóstico Diferencial: Transtornos Psiquiátricos da Infância, Transtorno Desafiador Oposicionista e Transtorno de Conduta, Transtorno do Humor Bipolar, Transtorno Obsessivo-Compulsivo e Transtorno de Tiques, Transtorno de Ansiedade, Transtornos Neurológicos da Infância, TDAH e Epilepsia, Transtornos do Aprendizado, Processamento Auditivo e Transtornos de Linguagem. 4) Tratamentos: Psicoterapia de Crianças, Psicoterapia de Adultos, Treinamento de Pais, Coaching, Prognóstico, Psicofarmacoterapia.

Na seção 1, o leitor encontrará revisões amplas e atuais da literatura sobre a epidemiologia, a neuroquímica, a genética e os aspectos neuropsicológicos do TDAH, além de obter conhecimentos sobre a neurofisiologia da memória e da atenção, e a questão da escola e da família. Um exemplo é o relato histórico completo da síndrome, desde as primeiras observações de Hoffmann, psiquiatra alemão autor de contos infantis, passando pelas primeiras descrições de casos clínicos de Still no Lancet, em 1902, e acompanhando as diversas transformações na descrição da síndrome e dos nomes que recebeu ao longo do tempo, sob influência das mudanças na nosologia psiquiátrica e na compreensão de possíveis fatores etiológicos do TDAH. A epidemiologia do transtorno é bem apresentada, incluindo uma discussão sobre a amplitude da diferença entre os diversos estudos epidemiológicos e suas 
possíveis razões. São apresentados ainda os principais modeIos neuroquímicos aceitos atualmente para o TDAH e a circuitaria cerebral envolvida. As disfunções executivas e os mais recentes estudos de genética molecular do TDAH, a partir das pesquisas com alelos dos genes que codificam alguns dos receptores de dopamina, são também apresentados. O clínico receberá informações relevantes sobre o papel da família e da escola, quer como fontes de informação, quer como coadjuvantes no tratamento.

A seção 2 é composta de cinco capítulos. No primeiro, "O Exame Psiquiátrico da Criança", o leitor será guiado passo a passo no processo de conduzir uma entrevista clínica com crianças através de diversos relatos de casos e exemplos das principais perguntas a serem feitas, com a didática reveladora da experiência clínica do autor e da naturalidade com que exerce sua prática. O capítulo seguinte, sobre o exame neurológico da criança, é simples e direto, sugerindo ao clínico a observação de alterações sutis que podem estar presentes no TDAH, bem como das alterações sugestivas de outro diagnóstico. O próximo capítulo discorre sobre a adolescência, com seus comportamentos característicos, e as dificuldades trazidas pelo TDAH nessa fase da vida. No capítulo sobre TDAH em adultos, o leitor aprenderá como os sintomas do TDAH se transformam ao longo da vida, o que dificulta a aplicação de critérios diagnósticos em adultos e torna ainda mais necessário um bom conhecimento da clínica do TDAH e do funcionamento na vida que seus portadores apresentam, muito bem apresentado pelo autor, que demonstra experiência ainda rara em nosso meio. O capítulo seguinte aborda o impacto do TDAH na vida conjugal, na família e no trabalho.

$\mathrm{Na}$ seção 3, o leitor encontrará informações suficientes sobre as principais condições que podem ser confundidas com o TDAH ou que comumente se sobrepõem a ele; dados epidemiológicos, quadros clínicos e as principais condutas terapêuticas encontram-se bem apresentados, atendendo plenamente aos objetivos de um Manual Clínico.

A última seção é completa, abrangendo todas as modalidades terapêuticas complementares à farmacoterapia que se revelaram eficazes para o TDAH. Um oportuno capítulo sobre técnicas de Coaching para TDAH vem suprir essa lacuna em nosso meio; muitos adultos com TDAH, mesmo em uso correto de medicamentos, permanecem com dificuldades de organização e planejamento e com tendência à procrastinação; o coach, ao desenvolver uma parceria saudável com o portador, ajudando-o a monitorar-se (a falta de automonitoração é fonte de grandes prejuízos na vida diária de um portador), estimulando-o e motivando-o a realizar e manter mudanças positivas em sua vida, é capaz de potencializar em muito os resultados do tratamento. Além disso, o coach aumenta a adesão ao tratamento, considerando que freqüentemente o portador de TDAH se esquece de tomar os medicamentos. O último capítulo do livro aborda as dúvidas mais comuns dos pais a respeito do uso de medicamentos, os fatores que podem influenciar a adesão ao tratamento, uma breve explicação sobre as catecolaminas cerebrais e os principais sistemas, os medicamentos utilizados, sua titulação e seus mais freqüentes efeitos adversos. Entre os medicamentos estimulantes (os mais eficazes e os mais prescritos para tratar o TDAH), o autor detalha as três apresentações comerciais diferentes de metilfenidato disponíveis no Brasil, o metilfenidato de curta ação, o de longa ação de absorção bimodal, e o de longa ação pelo sistema de liberação osmótica.
Baseado em parte na literatura, em parte em sua grande experiência no manejo desses fármacos, o autor apresenta dicas práticas de quando uma das apresentações é mais vantajosa que as outras, de como potencializar a adesão ao tratamento, de como lidar com os principais efeitos adversos, fazendo jus à proposta do Manual Clínico.

A alta prevalência, o elevado grau de prejuízo que acarreta ao longo da vida, o amplo espectro de problemas associados (índices mais elevados de acidentes automobilísticos, evasão escolar, perda de empregos, divórcio, dificuldades nos cuidados parentais, maiores gastos com saúde, etc.), o perfil de comorbidades freqüentemente presentes e o fato de haver um tratamento altamente efetivo fizeram do TDAH uma questão de saúde pública nos EUA. Aqui, freqüentemente ainda se discute se o TDAH de fato existe, ou se não se trata de uma invenção da indústria, ou se não é mais um modismo, e vez por outra vemos profissionais dando declarações inverídicas sobre o tema. Para nós, especialistas em TDAH, a desinformação, a falta de conhecimento histórico e o preconceito saltam aos olhos em opiniões como essas. Vivemos um momento em que o acesso à informação nunca foi tão fácil, principalmente devido à internet; com isso, muitos portadores de TDAH têm procurado ajuda de forma crescente em consultórios psiquiátricos e serviços públicos de saúde mental; é comum ouvirmos colegas recebendo pacientes que entendiam de TDAH mais do que eles mesmos. Infelizmente, a qualidade nem sempre boa da informação disponível, aliada à formação ainda precária dos profissionais, tem gerado críticas e relatos de possível excesso de diagnósticos. Na verdade, não existem diagnósticos excessivos e sim diagnósticos equivocados, ou que deixaram de considerar comorbidades que prejudicam a resposta ao tratamento. A considerar as taxas de prevalência estimada, o que predomina ainda é o subdiagnóstico. A necessidade de capacitar mais profissionais da área para o diagnóstico e tratamento do TDAH é premente.

O TDAH é o transtorno mental mais diagnosticado em crianças; sua persistência em adultos já está amplamente estabelecida na literatura e, no entanto, infelizmente, a maior parte dos psiquiatras de adultos não recebeu formação adequada para o seu diagnóstico e tratamento. A deficiência de formação decorre da concepção equivocada de que o TDAH seria um transtorno exclusivo de crianças e que teria remissão espontânea com o crescimento. Com isso, adultos portadores da síndrome e que sofrem com baixo desempenho e dificuldades de administrar a própria vida - e que muitas vezes, ao longo da vida, foram objeto de preconceito, escárnio ou avaliação equivocada - acabam perdendo a oportunidade de um diagnóstico e tratamento corretos. Essa obra tem o potencial de corrigir essa deficiência e, por isso, sua leitura é imperativa para todos os profissionais da saúde mental.

Marcos Romano

Ambulatório de TDAH, Unidade de Pesquisa em Álcool e Drogas (UNIAD), Universidade Federal de São Paulo (UNIFESP), São Paulo (SP), Brasil 